\title{
"SE EU NÃO TIVER A MINHA BATEIA, QUEM VAI DIZER QUE SOU GARIMPEIRA?": A MEMÓRIA, A IDENTIDADE E AS COISAS NO GARIMPO DE SERRA PELADA, AMAZÔNIA. ${ }^{1}$
}

\author{
Marcia Bezerra ${ }^{2}$ \\ Luis Ricardo Ravagnani ${ }^{3}$
}

Este ensaio fotográfico é resultado de experiência etnográfica entre os garimpeiros da Vila de Serra Pelada, estado do Pará, Amazônia. A ideia norteadora era a de mapear as relações entre as pessoas e as coisas, a partir das biografias de um grupo de narradores e seus artefatos memoriais, considerando a agência humana sobre os objetos e dos objetos sobre os humanos. Durante a pesquisa o repertório material do garimpo emergiu como matéria fundante no processo de constituição da identidade dos garimpeiros. Carteiras amareladas, pedaços das escadas dos barrancos, solas de kichutes, fragmentos de picaretas e bateias, fazem parte de coleções biográficas mantidas pelo que nelas há de individual, de vida vivida de cada um, e de coletivo, porque atuam como amálgama de histórias narradas por um sentimento de nostalgia que se con(funde) com a reivindicação de seus direitos mais humanos, e na qual a centralidade dos objetos revela que as coisas constroem as pessoas. (Miller 2005: 38)

Assim as ferramentas, atores não-humanos do garimpo, ativam a memória da comunidade de trabalho de D. Raimunda, ao mesmo tempo, em que tornam substantiva a condição de "ser garimpeira". Sua bateia é uma "extensão protética" (Gosden 2001: 164; Gell 1998) acionada num ato técnico performático em que o movimento do corpo, das mãos, dos dedos, acompanha uma narrativa devaneante, aniquiladora do tempo e instauradora de uma paisagem [de] retorno à quadra, ao barranco, à cava do garimpo.

D. Raimunda não quis apenas mostrar que "foi assim que aconteceu e que esteve lá", mas quis nos "levar lá", envolvendo-nos em seu transe, encenado ali no quintal de sua casa, momentaneamente, transfigurado no garimpo do passado e, no qual, o nosso olhar foi mobilizado como autenticador da performance técnica que legitima a sua identidade. Nessa "etnografia da suspensão" - suspensão do tempo, do espaço e dos papeis - tornamo-nos cúmplices, participantes; não mais, e apenas, observadores.

\footnotetext{
${ }^{1}$ Pesquisa realizada pelos autores no âmbito do Programa de Prospecções e Educação Patrimonial em Serra Leste, Curionópolis/PA. UFPA/Coord. Geral: D.P. Schaan.

${ }^{2}$ Universidade Federal do Pará, Brasil.

${ }^{3}$ Universidade Federal do Pará, Brasil.
} 


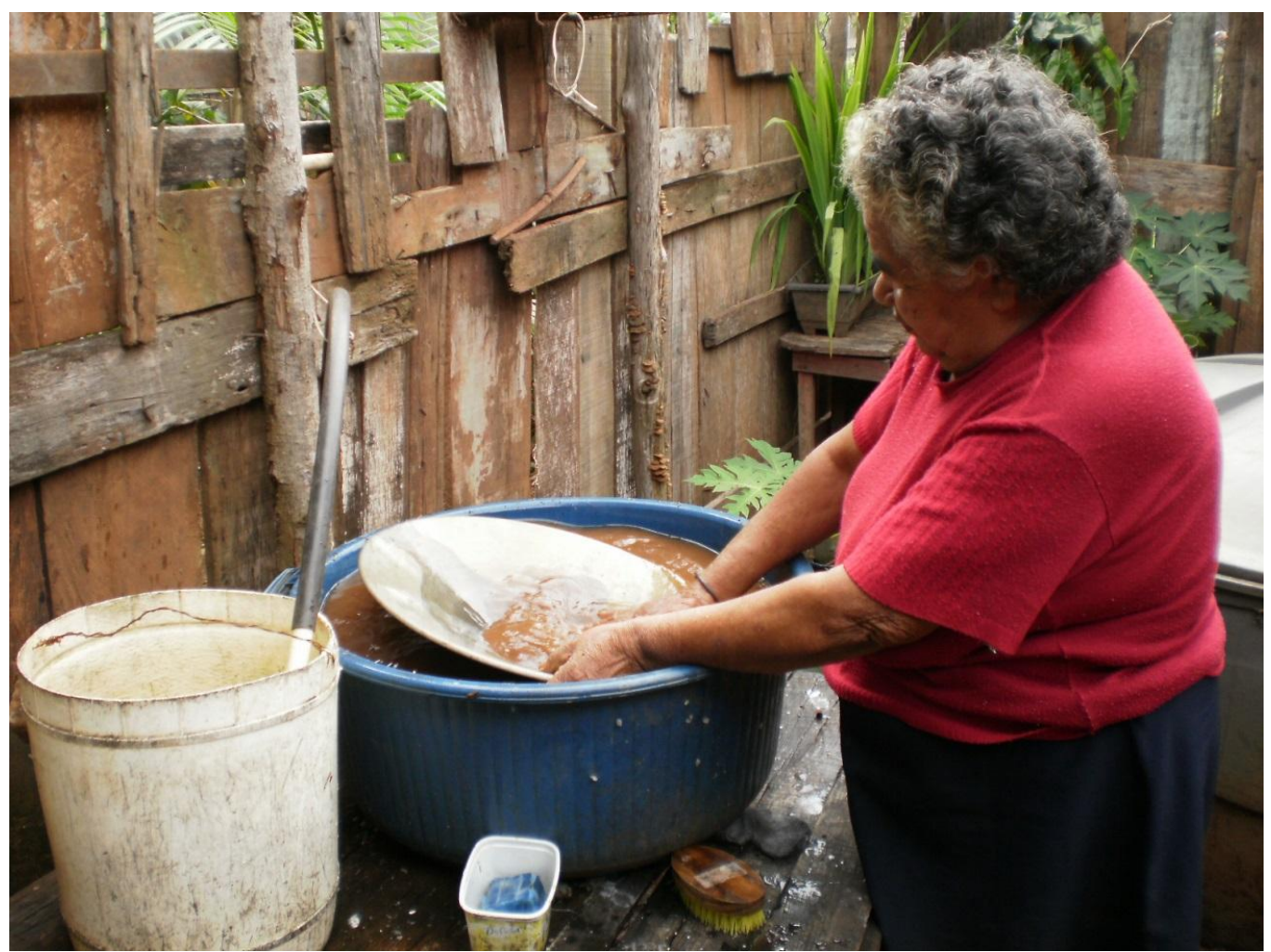

Figura 1 - Abertura - D. Raimunda e a Bateia. Foto: Marcia Bezerra.

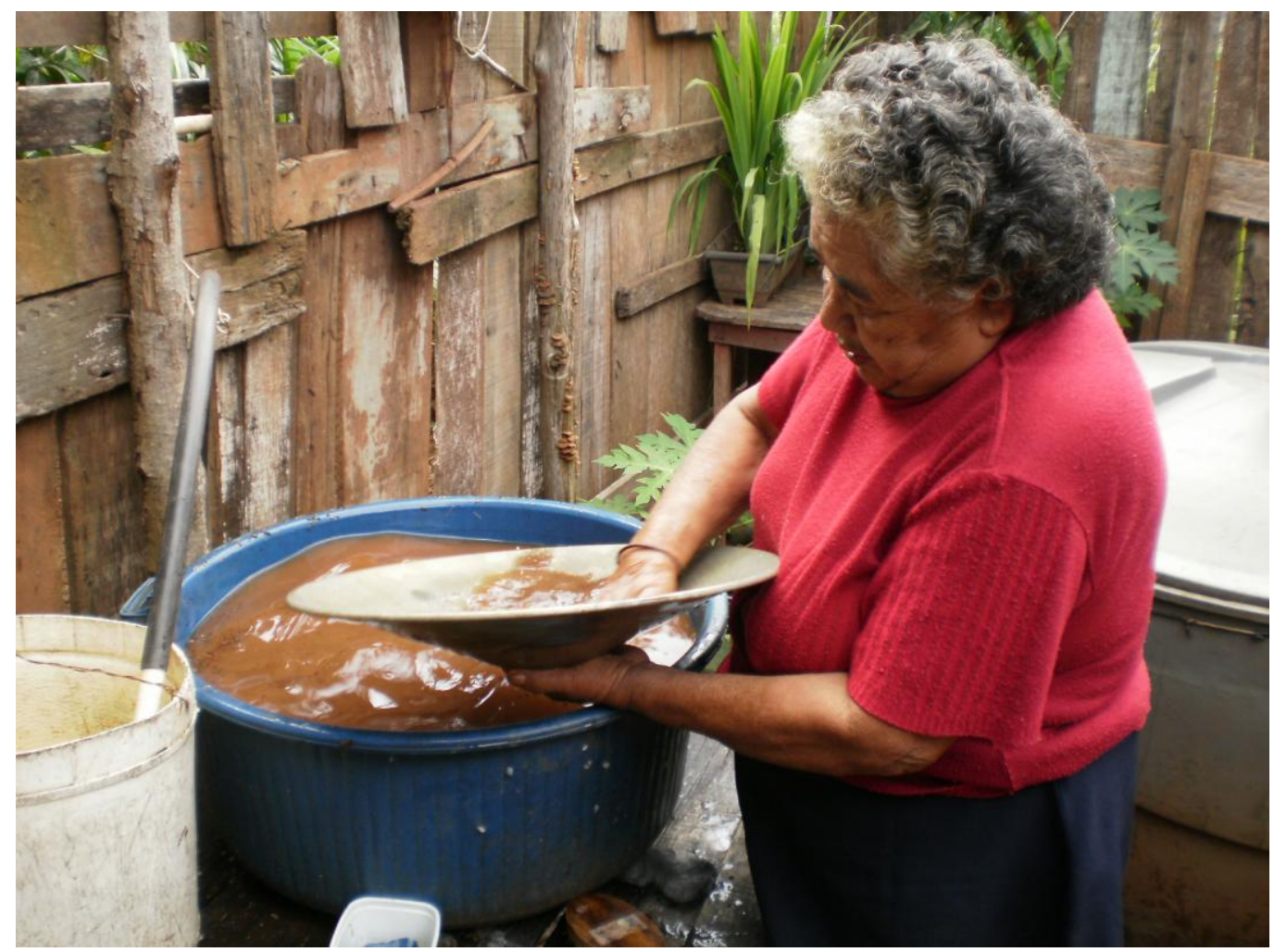

Figura 2 - $1^{\circ}$ Ato - Humanos e Não-Humanos. Foto: Marcia Bezerra 


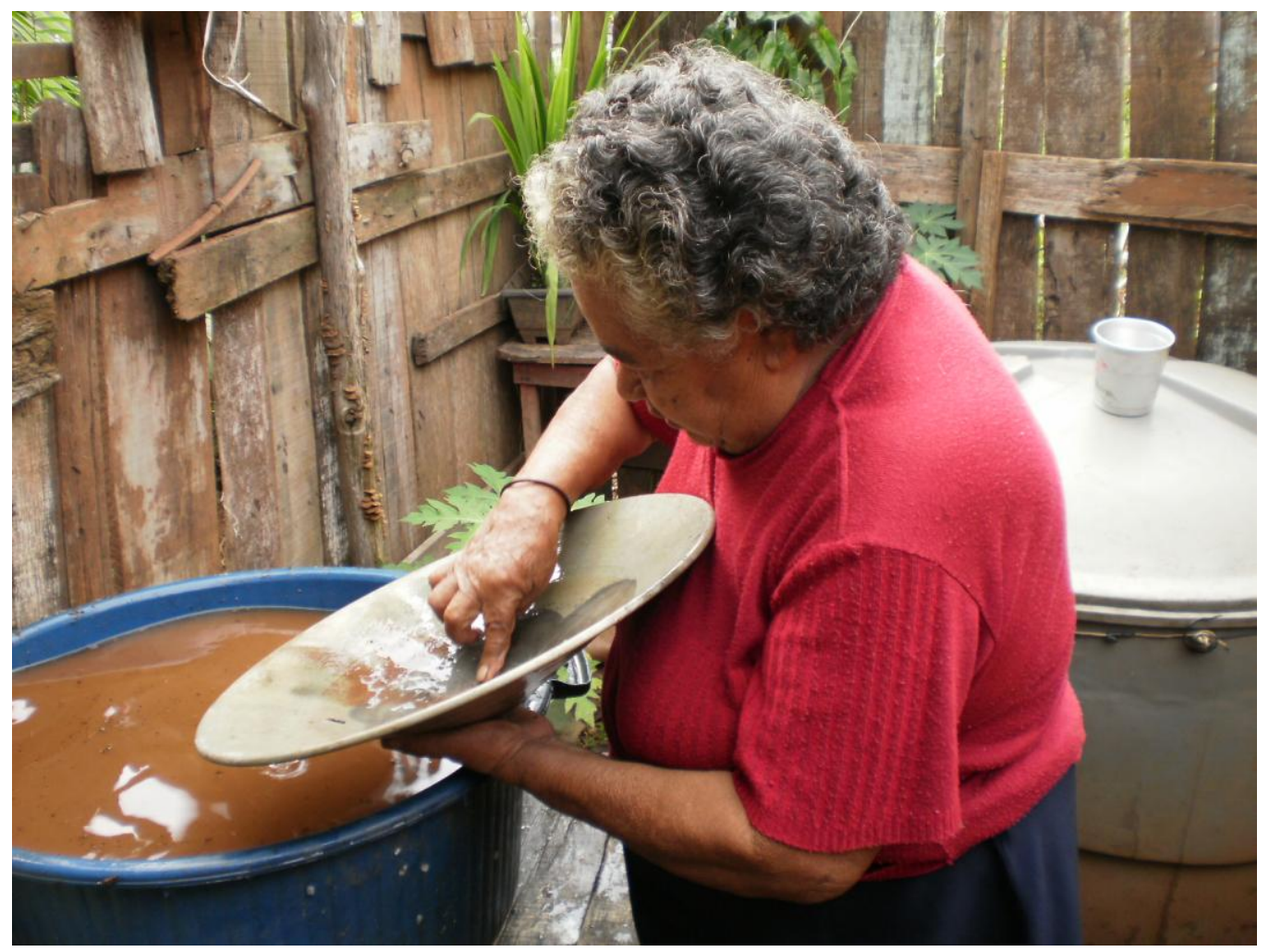

Figura 3 - $2^{\circ}$ Ato - Corpo Técnico. Foto: Marcia Bezerra

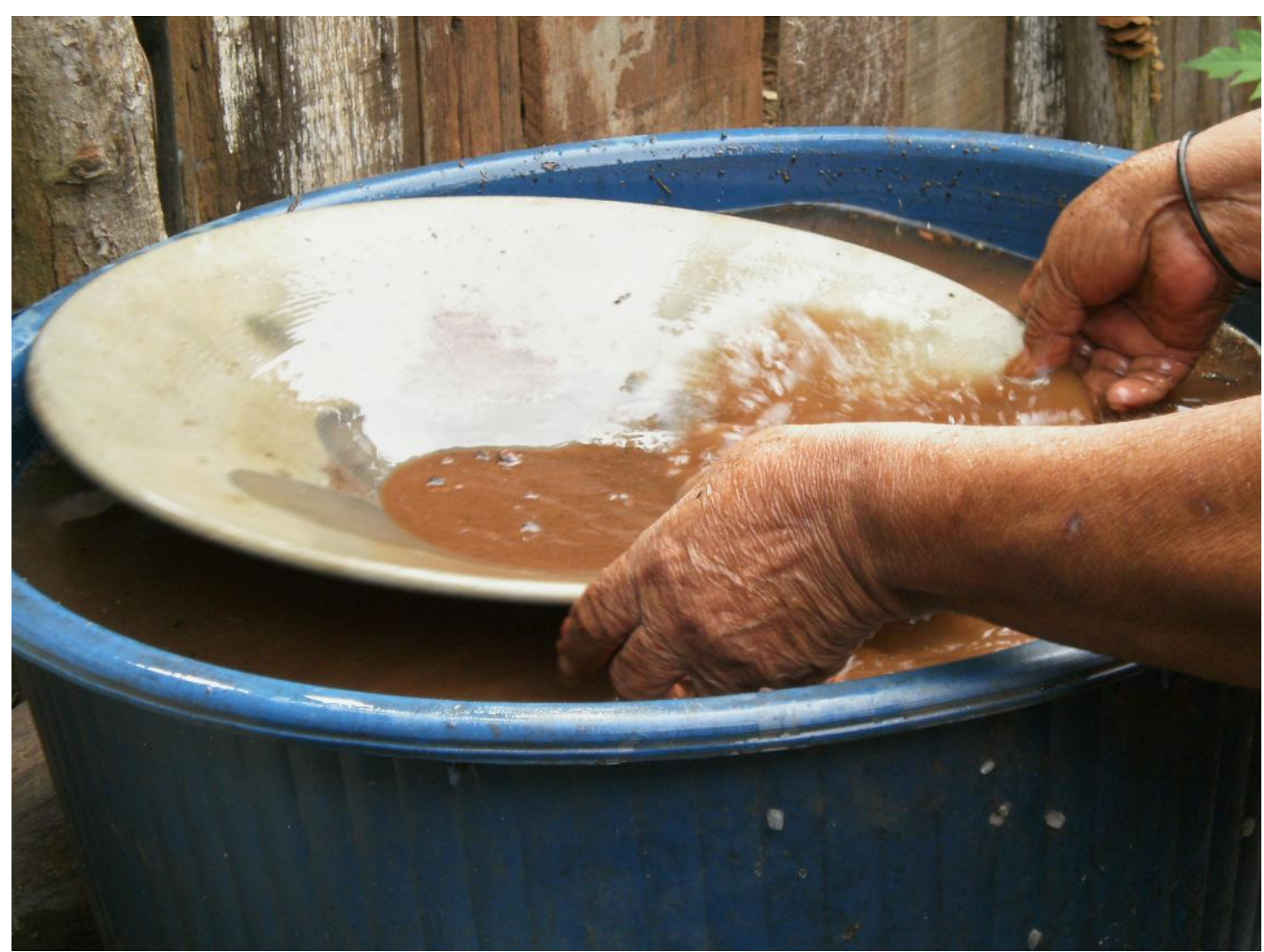

Figura 4 - $3^{\circ}$ Ato - Em suspensão. Foto: Marcia Bezerra

Iluminuras, Porto Alegre, v. 14, n. 34, p. 355-360, ago./dez. 2013 


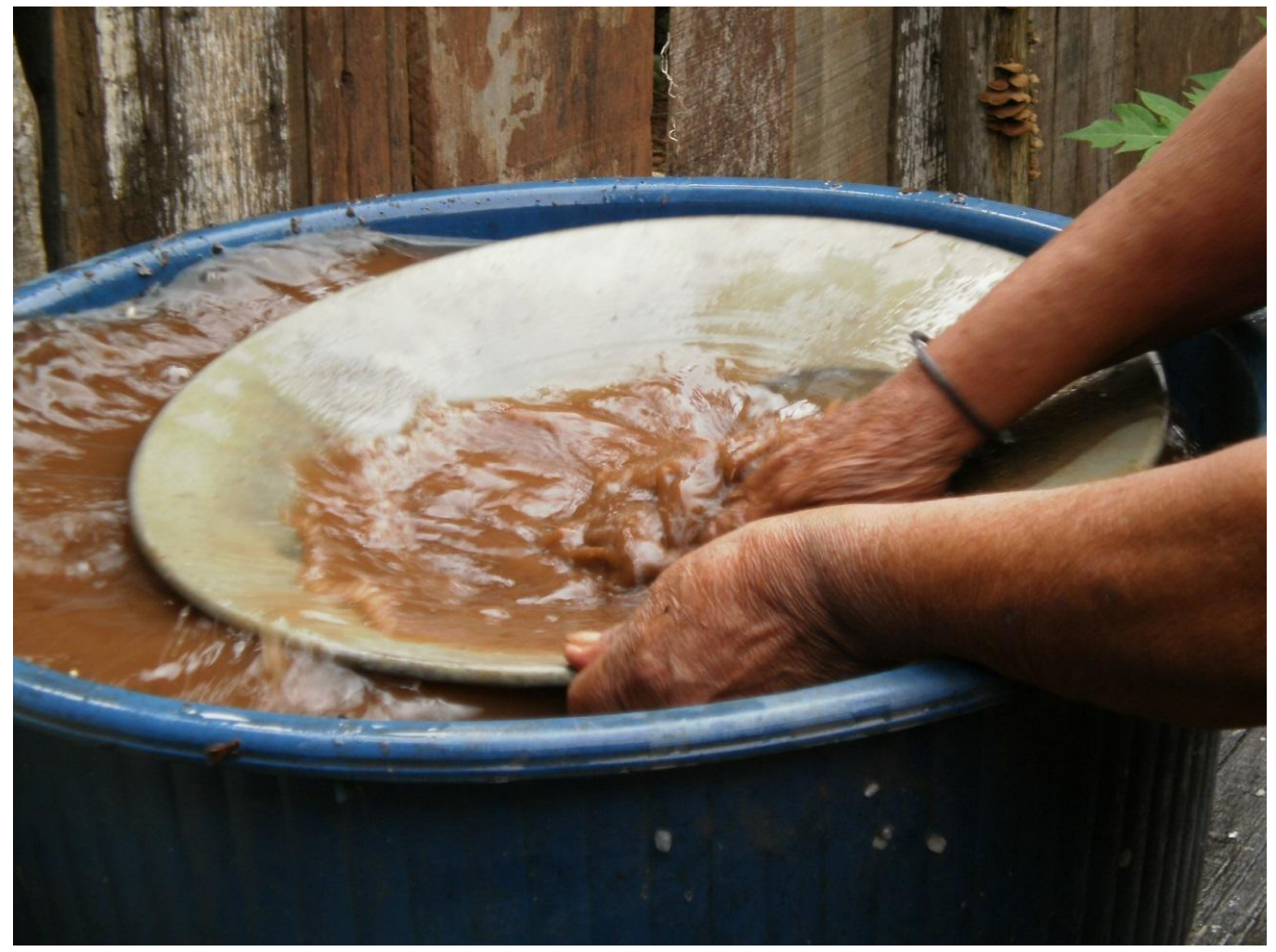

Figura 5 - $4^{\circ}$ Ato - Em transe. Foto: Marcia Bezerra

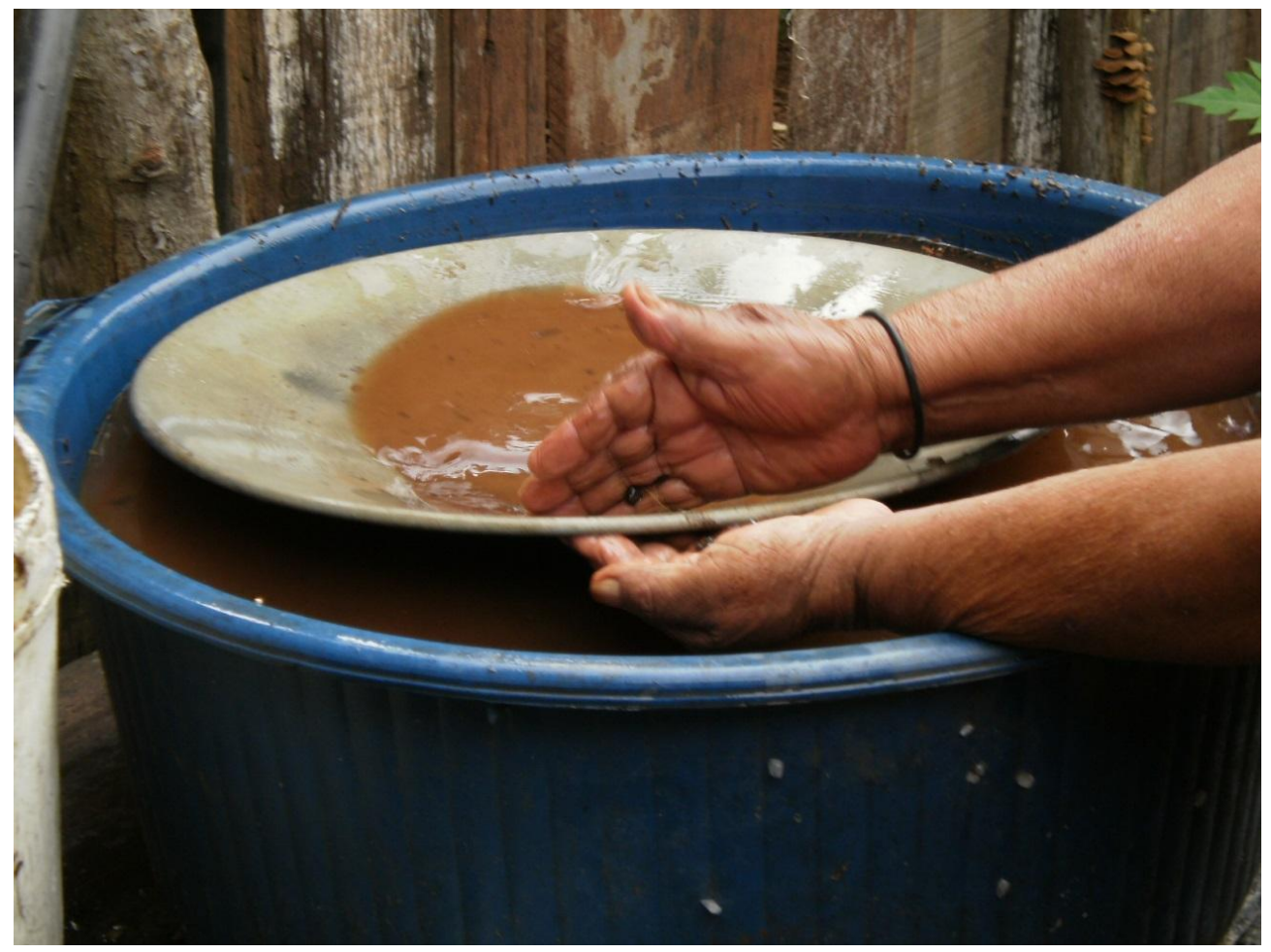

Figura 6 - $5^{\circ}$ Ato - Retorno. Foto: Marcia Bezerra

Iluminuras, Porto Alegre, v. 14, n. 34, p. 355-360, ago./dez. 2013 


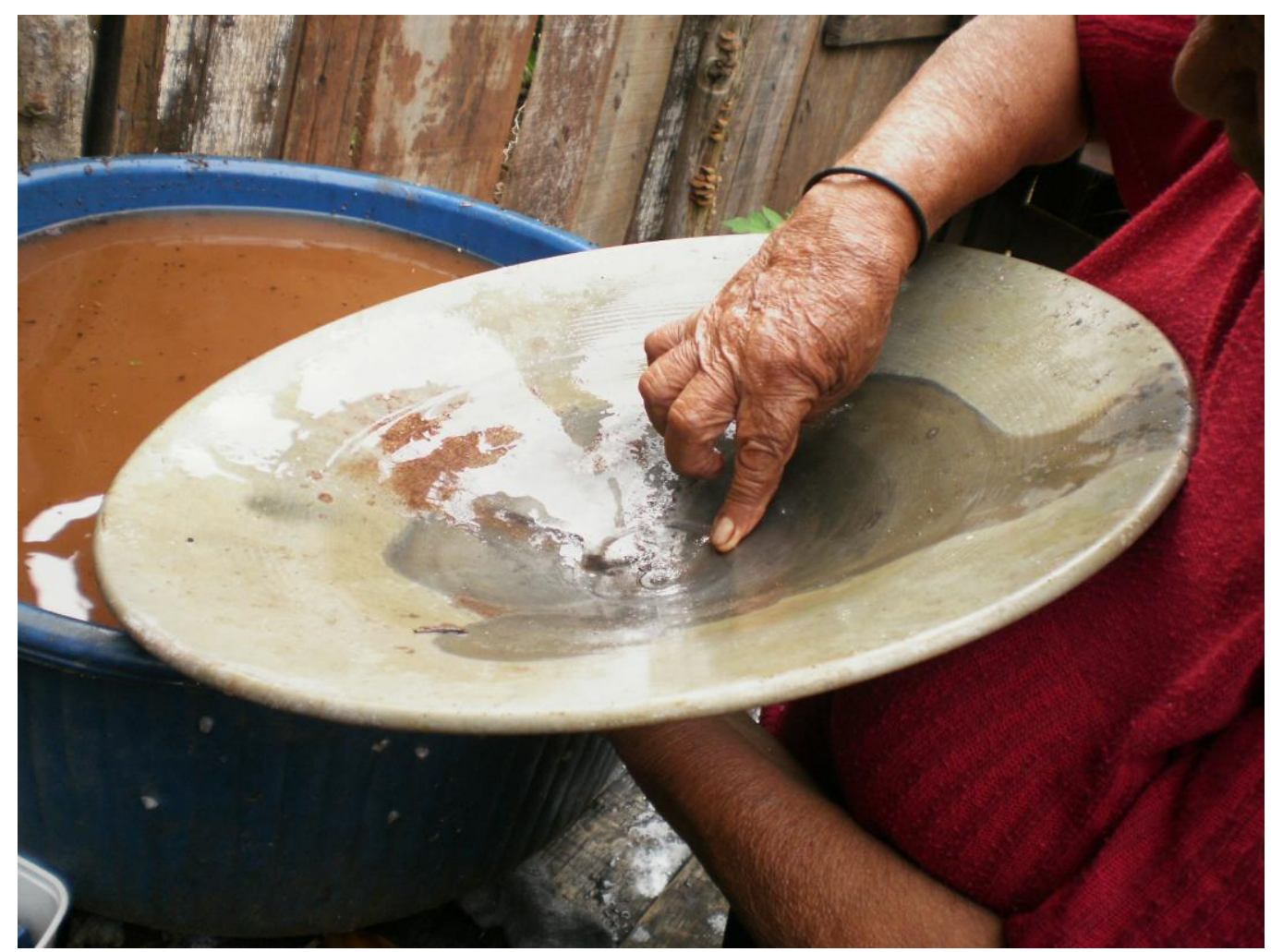

Figura 7 - $6^{\circ}$ Ato - Extensão Protética. Foto: Marcia Bezerra

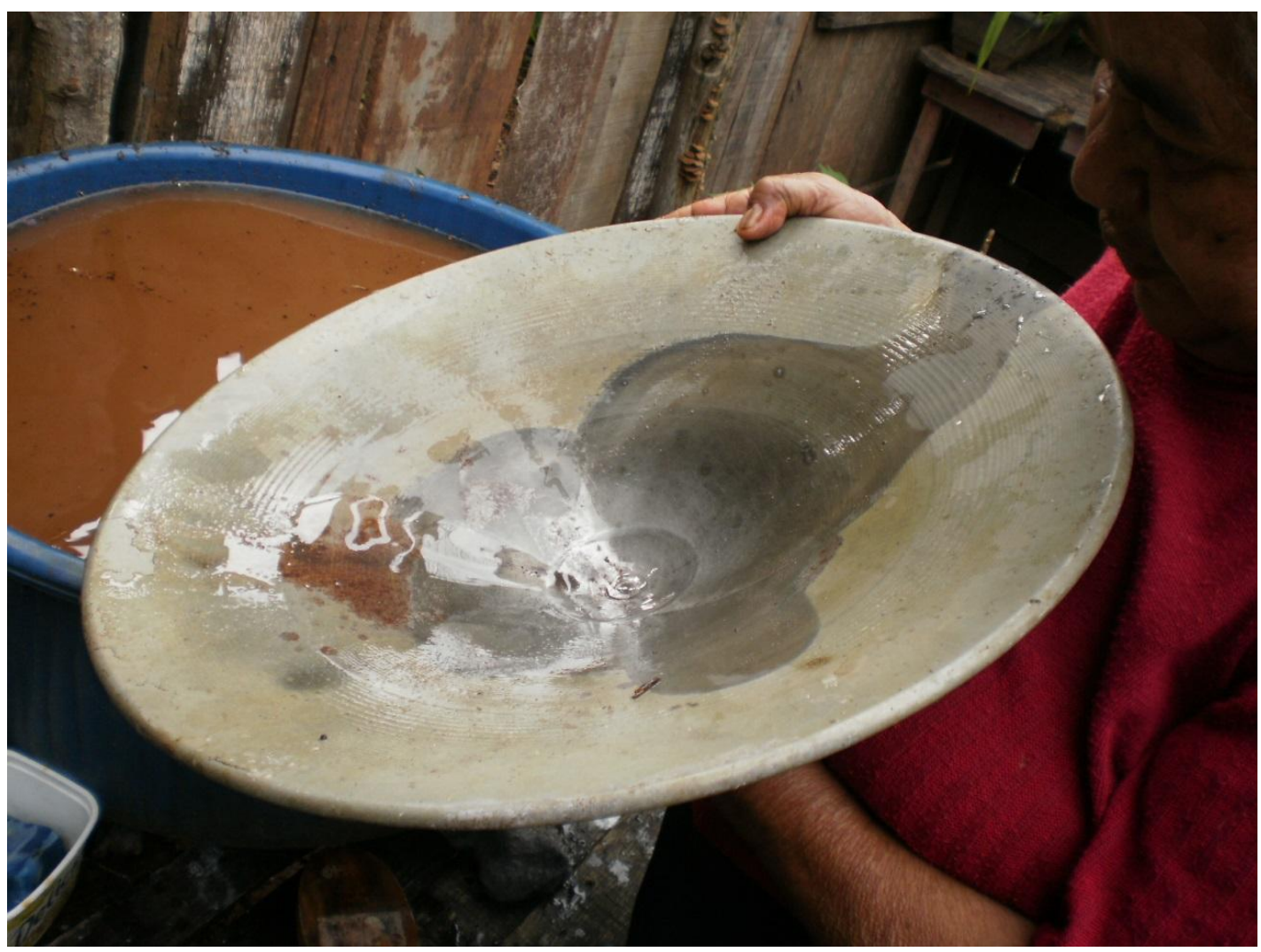

Figura 8 - Ato Final - Ser Garimpeira. Foto: Marcia Bezera

Iluminuras, Porto Alegre, v. 14, n. 34, p. 355-360, ago./dez. 2013 


\section{Referências}

GELL, A. Art and Agency: an anthropological theory. New York: Oxford University Press, 1998.

GOSDEN, C. Making Sense: Archaeology and Aesthetics. World Archaeology 33:163-167, 2001.

MILLER, D. (Ed.). Materiality. Durham: Duke University Press, 2005.

Recebido em: 10/11/2013

Aprovado em: 21/11/2013 